\title{
Assessment on Physical and Rheological Properties of Aged SBS Modified Bitumen Containing Rejuvenating Systems of Isocyanate and Epoxy Substances
}

\author{
Zhelun $\mathrm{Li}^{1}{ }^{1}$, Xiong $\mathrm{Xu}{ }^{2, *} \mathbb{D}$, Jianying $\mathrm{Yu}^{1, *}$ and Shaopeng $\mathrm{Wu}^{1}$ \\ 1 State Key Laboratory of Silicate Materials for Architectures, Wuhan University of Technology, Wuhan \\ 430070, China; lizhelun@whut.edu.cn (Z.L.); wusp@whut.edu.cn (S.W.) \\ 2 School of Civil Engineering and Architecture, Wuhan Institute of Technology, Wuhan 430074, China \\ * Correspondence: xxucea@wit.edu.cn (X.X.); jyyu@whut.edu.cn (J.Y.); \\ Tel.: +86-158-7171-9331 (X.X.); +86-133-6728-9333 (J.Y.)
}

Received: 1 January 2019; Accepted: 13 February 2019; Published: 19 February 2019

\begin{abstract}
Styrene-butadiene copolymer (SBS)-modified bitumen (SMB) is widely applied in pavement construction. With yearly services, many SMB wastes urgently need to be reclaimed for repaving roads based on the objectives of environmental protection, landfill saving, as well as resource utilization. The present work is focused on the investigation of the physical and rheological properties of aged SMB incorporated with rejuvenating systems consisting of fluid catalytic cracking slurry (FCC slurry), C12-14 aliphatic glycidyl ether (AGE), diphenylmethane diisocyanate (MDI), and other additives. The rejuvenating systems containing the main components of $10 \%$ FCC slurry, $10 \%$ FCC $/ 3 \%$ AGE, and $10 \%$ FCC $/ 3 \%$ AGE $/ 1 \%$ MDI were respectively recorded as $R_{a}, R_{b}$, and $R_{c}$. The results indicate that both $R_{b}$ and $R_{c}$ have obvious workability that make contributions for improving comprehensive physical properties while slightly reducing the softening point, which were also proven to be effective for the re-rejuvenation of re-aged binder. The higher viscous-elastic temperature caused by the agglomeration of binder molecules in aged SMB could be dropped to a lower value with rejuvenating systems, while improving the low-temperature crack resistance. With the use of the $R_{b}$ and $R_{c}$ rejuvenating systems, the high-temperature deformation resistance of aged SMB fell, approaching the performance of fresh SMB. Vibration noise consumption could be improved for aged SMB incorporated with $R_{b}$ and $R_{c}$ in the form of viscous loss, while the effects for re-aged SMB containing the same rejuvenating systems were weakened but still effective.
\end{abstract}

Keywords: SBS-modified bitumen; rejuvenating systems; physical properties; viscous-elastic temperature; rutting factor; vibration noise consumption

\section{Introduction}

Along with the booming development of highway construction in China, tri-block styrene-butadiene copolymer (SBS)-modified bitumen is widely applied in high-class pavement due to its advantageous high- and low-temperature performance, driving comfort, smooth surface, and abrasive resistance [1-4]. Despite that, during the in-service period, a series of physical and chemical changes resulting in the performance deterioration of SBS-modified bitumen (SMB) occur under the comprehensive effect of the natural environment such as heat, UV, oxygen, and rainwater [5-8]. Furthermore, a great deal of waste SMB is constantly produced and causes huge resource and landfill waste as well as environmental hazards $[9,10]$. Accordingly, the problem of high-quality rejuvenation for waste SMB urgently needs to be solved. 
The aging of SMB includes not only oxidation and poly-condensation of base bitumen, but also the oxidative degradation of SBS, which differs from the aging of base bitumen [11]. Owing to the oxidative degradation of SBS, the road performances of SMB after long-term aging significantly drop to hardly meet standardized requirements [12-15]. Thus, the consideration regarding the comprehensive performance recovery of SMB should be taken for both aged bitumen and aged SBS. As of now, some publications have reported that the rejuvenation of aged SMB can be realized by adding fresh SMB and/or rich aromatic oils [16-20]. For instance, Gong et al. investigated the physical and chemical properties of aged SMB mixed with bio-oil derived from biodiesel residue, and discovered that the bio-oil could be used to achieve the goal of rejuvenating aged SMB and enhance its physical properties, while mitigating the highly-oxidized components aggregated and dispersing the asphalt molecules [21]. Chen et al. conducted a study using waste edible vegetable oil to rejuvenate aged asphalt binder containing SBS by testing the physical and rheological properties, and found that waste edible vegetable oil is suitable for the recycling of aged SBS modified asphalt with the result of better performance recovery [22].

Although these kinds of physical components have some advantages in restoring most of the properties of aged $\mathrm{SMB}$, the performance recovery is only for aged bitumen binder and not aged polymer. In fact, some publications have reported that the oxidation and degradation of SBS would simultaneously occur during the oxidative aging step, with the destructed polymer pieces forming with oxygen-containing groups such as hydroxyl and carbonyl groups [23-26]. Considering the use of those groups, we propose an in-situ chemical reaction to amend the molecular structure of SBS polymer in order to improve the properties of bitumen binder. In view of this emerging idea, the novelty differs from other reports in trying to use the reactive components to make a partial connection among degraded polymer, and the high aromatic mixtures to adjust the chemical composition of aged virgin bitumen are both involved.

This present work aims to solve the issue of high-quality recycling of aged SMB by using the selected rejuvenating system consisting of fluid catalytic cracking slurry (FCC slurry), C12-14 aliphatic glycidyl ether (AGE), diphenylmethane diisocyanate (MDI), and other additives. The physical and rheological properties of aged SMB incorporating the rejuvenating systems were systematically investigated, and the re-rejuvenation effects of the selected rejuvenating system are discussed and analyzed.

\section{Experimental}

\subsection{Raw Materials}

The used SBS modified bitumen (SBS/bitumen, 5/100) was obtained in the laboratory by mixing linear SBS (1301, S/B = 30/70) and base bitumen (SK-70). FCC slurry was selected to improve the chemical components of aged bitumen binder. The relative mass percentages in saturates, aromatics, resins, and asphaltenes were $8.82 \%, 75.23 \%, 7.93 \%$, and $8.02 \%$, respectively. AGE is a low-viscosity end-epoxy molecule that can penetrate into the binder and disperse the agglomeration formed from aging. MDI was selected to limit the dropping high-temperature properties of rejuvenated SMB through the chemical consolidation reaction.

\subsection{Aging Procedure of $S M B$}

The evenly dispersed SMB specimens were standardly prepared for pressure aging vessel (PAV) aging. The aging experiments were as follows in order of the thin film oven test (TFOT, referring to ASTM D1754) and the PAV test (referring to ASTM D6521) [27], the lab conditions of which were $163{ }^{\circ} \mathrm{C} \times 5 \mathrm{~h}$ and $100{ }^{\circ} \mathrm{C} \times 2.1 \mathrm{MPa} \times 20 \mathrm{~h}$ (in air atmosphere) to simulate the short-term mixing and paving process and the long-term working aging of SMB, respectively. 


\subsection{Rejuvenation for Aged $S M B$}

The aged SMB specimens above were quantitatively weighed and shifted to an agitated vessel for hot mix rejuvenation. Until the stable temperature of $150{ }^{\circ} \mathrm{C}$ was reached, the low-speed agitation started, while 10\% FCC slurry, 3\% AGE and other low amounts of additives with or without 1\% MDI were respectively mixed into the binder for $20 \mathrm{~min}$ to prepare three kinds of rejuvenated SMB. The rejuvenating systems containing the main components of $10 \%$ FCC slurry, $10 \% \mathrm{FCC} / 3 \% \mathrm{AGE}$, and $10 \%$ FCC $/ 3 \%$ AGE $/ 1 \%$ MDI are respectively abbreviated as $R_{a}, R_{b}$, and $R_{c}$ for reference in this manuscript.

\subsection{Tests for Physical Properties}

The physical properties of various SMB specimens as mentioned above, included viscosity at 135 ${ }^{\circ} \mathrm{C}$, softening point, penetration at $25^{\circ} \mathrm{C}$, and ductility at $5{ }^{\circ} \mathrm{C}$ were measured according to ASTM D4402, ASTM D36, ASTM D5, and ASTM D113, respectively [28-31]. Additionally, the experimental results of the primary physical properties of fresh and PAV-aged SMB are presented in Table 1.

Table 1. Primary physical properties of styrene-butadiene copolymer modified bitumen (SMB) before and after pressure aging vessel (PAV) aging.

\begin{tabular}{ccc}
\hline Technical Index & Fresh SMB & PAV-Aged SMB \\
\hline Ductility at $5^{\circ} \mathrm{C}(\mathrm{cm})$ & 36.8 & 1.2 \\
Softening point $\left({ }^{\circ} \mathrm{C}\right)$ & 70.5 & 63.1 \\
Viscosity at $135^{\circ} \mathrm{C}(\mathrm{Pa} \cdot \mathrm{s})$ & 2.56 & 2.85 \\
Penetration at $25^{\circ} \mathrm{C}(\mathrm{dmm})$ & 48 & 17 \\
\hline
\end{tabular}

\subsection{Tests for Rheological Properties}

The rheological characteristics of the various SMB specimens mentioned above were tested using a dynamic shear rheometer (DSR, MCR101, Anton Paar, Graz, Austria). The tests for rheological properties were conducted under strain-controlled conditions at $10 \mathrm{rad} / \mathrm{s}$ with the heat rate of $2{ }^{\circ} \mathrm{C} / \mathrm{min}$ between the temperature ranges of -10 and $80^{\circ} \mathrm{C}$. During the test, plates with an $8 \mathrm{~mm}$ diameter and a $2 \mathrm{~mm}$ gap below $30^{\circ} \mathrm{C}$ and plates with a $25 \mathrm{~mm}$ diameter and a $1 \mathrm{~mm}$ gap above $30{ }^{\circ} \mathrm{C}$ were respectively used. According to the manufacturing specifications, related rheological parameters such as elastic modulus $\left(G^{\prime}\right)$, viscous modulus $\left(G^{\prime \prime}\right)$, complex modulus $\left(G^{*}\right)$, phase angle $(\delta)$, and rutting factor $\left(G^{*} / \sin \delta\right)$ were simultaneously obtained to assess the rheological properties of rejuvenated SMB.

\section{Results and Discussion}

\subsection{Effect of Rejuvenating Systems on the Physical Properties of Aged SMB}

Table 2 presents the related experimental results regarding the physical properties and recovery rates of aged SMB incorporating rejuvenating systems. From the table, with rejuvenating systems, the improvement on the ductility and penetration of aged SMB was clearly visible, while the softening point and viscosity both dropped to some extent. The differences in the physical properties of rejuvenated SMB containing $R_{a}, R_{b}$, and $R_{c}$ were easily observed in that $R_{b}$ and $R_{c}$ had significant advantages in making contributions to the ductility recovery, penetration recovery, and viscosity reduction of aged SMB - except for the softening point-in comparison with $R_{a}$. The explanation for the results is that the epoxy components play a vital effect in diffusing and dispersing the agglomerated substances of the aged binder. Meanwhile, compared with $R_{b}$, the slight weakness of $R_{c}$ for improving the physical properties is the reaction consolidation caused between MDI and aged SMB.

Furthermore, the data show that the use of $R_{b}$ and $R_{c}$ for aged SMB promoted ductility recovery rates approaching $76.6 \%$ and $67.1 \%$, penetration recovery rates of $112.5 \%$ and $95.9 \%$, the viscosity indexes were $37.5 \%$ and $49.2 \%$, and the softening point retention rates were $71.6 \%$ and $79.1 \%$ while the 
results of rejuvenated SMB containing $\mathrm{R}_{\mathrm{a}}$ were respectively $37.0 \%, 70.8 \%, 44.9 \%$, and $79.7 \%$. The data shown here indicate that the rejuvenating systems containing AGE with or without MDI can work better to both restore the physical properties of aged SMB and obtain rejuvenated SMB with various behaviors suitable for re-application.

Table 2. Physical properties and recovery rates of aged SMB incorporating rejuvenating systems.

\begin{tabular}{cccccc}
\hline \multirow{2}{*}{ Technical Index } & \multirow{2}{*}{ Aged SMB } & \multicolumn{3}{c}{ Rejuvenated SMB } & \multirow{2}{*}{ Equation } \\
\cline { 3 - 5 } & & $\mathbf{R}_{\mathbf{a}}$ & $\mathbf{R}_{\mathbf{b}}$ & $\mathbf{R}_{\mathbf{c}}$ & \\
\hline Ductility at $5{ }^{\circ} \mathrm{C}(\mathrm{cm})$ & 1.2 & 13.6 & 28.2 & 24.7 & - \\
Softening point $\left({ }^{\circ} \mathrm{C}\right)$ & 63.1 & 56.2 & 50.5 & 55.8 & - \\
Penetration at $25^{\circ} \mathrm{C}(\mathrm{dmm})$ & 17 & 34 & 54 & 47 & - \\
Viscosity at $135^{\circ} \mathrm{C}(\mathrm{Pa} \cdot \mathrm{s})$ & 2.85 & 1.15 & 0.96 & 1.26 & - \\
Ductility recovery rate $(\%)$ & - & 37.0 & 76.6 & 67.1 & \\
Softening point retention rate $(\%)$ & - & 79.7 & 71.6 & 79.1 & \multirow{2}{*}{$\mathrm{PCR}=\frac{P_{R}}{P_{F}} \times 100 \%$} \\
Penetration recovery rate $(\%)$ & - & 70.8 & 112.5 & 95.9 & \\
Viscosity index $(\%)$ & - & 44.9 & 37.5 & 49.2 & \\
\hline
\end{tabular}

Note: In the equation, PCR refers to the performance recovery ratio for rejuvenated binder; $P_{R}$ refers to the value for physical properties of rejuvenated binder; and $\mathrm{P}_{\mathrm{F}}$ refers to the value for the physical properties of fresh binder.

\subsection{Effect of Rejuvenating Systems on the Physical Properties of Second Aged SMB}

Figures 1-4 display the physical properties of ductility, softening point, penetration, and viscosity of aged SMB containing $R_{b}$ and $R_{c}$, respectively. It is clear that rejuvenated SMBs containing $R_{b}$ or $R_{c}$, after second aging, almost lost their low-temperature ductility, accompanied by a rise in the softening point. When $R_{b}$ and $R_{c}$ were selected again for the rejuvenation of second-aged SMB, the ductility increased by 23.7 and $20.2 \mathrm{~cm}$ with the recovery rates of $67.7 \%$ and $57.6 \%$, while the softening point decreased by $5.1{ }^{\circ} \mathrm{C}$ and $3.4^{\circ} \mathrm{C}$ with retention rates of $74.5 \%$ and $80.6 \%$. The results indicate that the rejuvenating system can, to some degree, restore the low-temperature properties of second-aged SMB and depress the significant deterioration of high-temperature properties.

Meanwhile, the penetration increased by $25 \mathrm{dmm}$ and $21 \mathrm{dmm}$ with recovery rates of $97.9 \%$ and $83.3 \%$, which illustrates that the use of these kinds of rejuvenating systems was still effective in restoring the penetration of second-aged SMB. Lastly, the results of the viscosity index $(46.1 \%$ and $65.2 \%$ ) show that the viscous behavior of second-aged SMB were improved using $R_{b}$, and increased with the addition of MDI. In other words, the use of $R_{c}$ was effective in restoring the low-temperature properties and limited the sharp fall of high-temperature properties for the second-aged SMB. To conclude, both $R_{b}$ and $R_{c}$ had good working abilities for recycling re-aged SMB in order to achieve better properties.

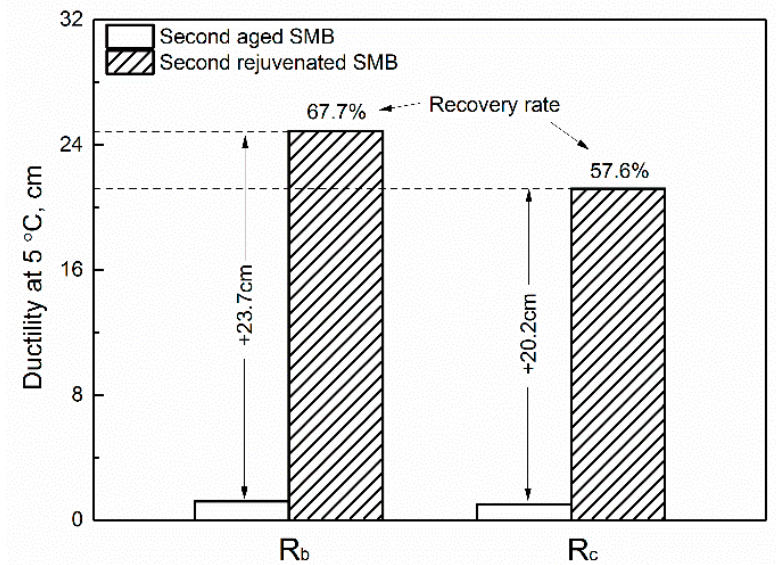

Figure 1. Effect of rejuvenating systems on the ductility of second-aged SMB. 


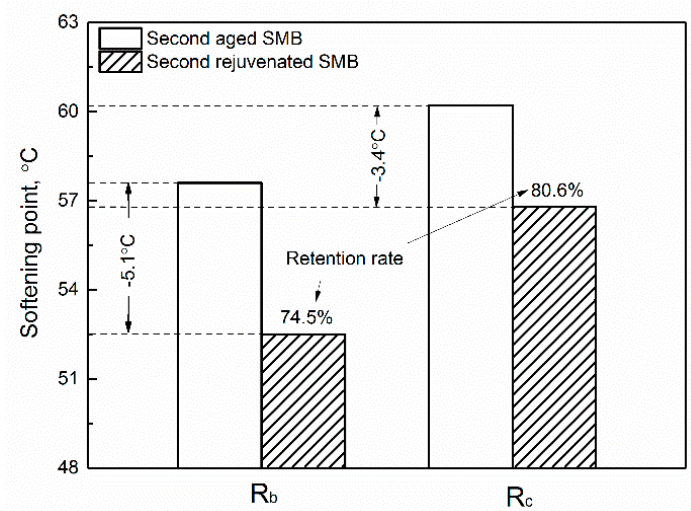

Figure 2. Effect of rejuvenating systems on the softening point of second-aged SMB.

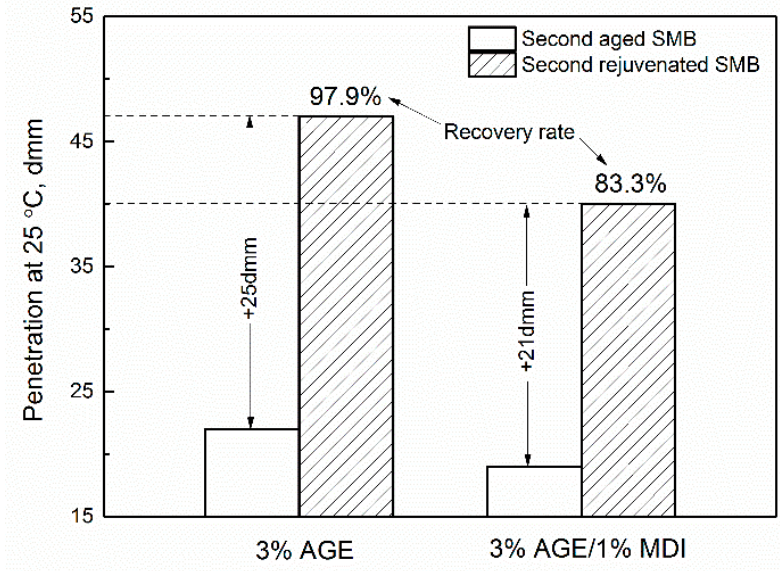

Figure 3. Effect of rejuvenating systems on the penetration of second-aged SMB.

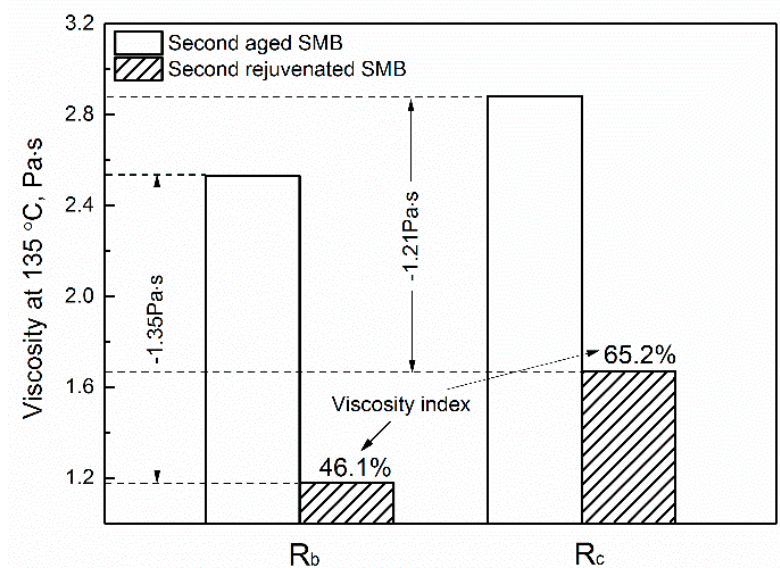

Figure 4. Effect of rejuvenating systems on the viscosity of second-aged SMB.

\subsection{Effect of Rejuvenating Systems on the Viscous-Elastic Behavior of Aged SMB}

The viscous-elastic characteristics of aged SMB with incorporated rejuvenating systems are presented in Figure 5. As depicted in Figure 5a, the values of $\mathrm{G}^{\prime}$ and $\mathrm{G}^{\prime \prime}$ of fresh SMB after aging increased, and the viscous-elastic temperature shifted to a higher level from $14.6{ }^{\circ} \mathrm{C}$ to $24.2{ }^{\circ} \mathrm{C}$, indicating that the deformation resistance of fresh SMB increased during the aging period, causing the viscous portion $\left(\mathrm{G}^{\prime \prime}\right.$ after $14.6^{\circ} \mathrm{C}$ ) of fresh $\mathrm{SMB}$ to tend to the harder portion before $24.2{ }^{\circ} \mathrm{C}$. From Figure $5 b$, it can be clearly seen that the values of $G^{\prime}$ and $G^{\prime \prime}$ of rejuvenated SMB were to some extent lower than the aged one, and the viscous-elastic temperature of aged SMB decreased with the addition of rejuvenators. Compared with $R_{a}$, the exhibited viscous behaviors of $R_{b}-$ and 
$\mathrm{R}_{\mathrm{C}}$-rejuvenated SMB were more obvious, the viscous-elastic temperatures of which decreased to $8.1^{\circ} \mathrm{C}$ and $12.1^{\circ} \mathrm{C}$, respectively. The findings illustrate that rejuvenating systems such as $R_{b}$ and $R_{c}$ provide the benefit of activating the hard components in aged SMB to the viscous components, and improve the low-temperature crack resistance. The reason for the higher viscous-elastic temperature of rejuvenated SMB containing $R_{c}$ depends upon the chemical reactions between the isocyanate groups and the formed reactive groups (e.g., $-\mathrm{OH}$ and $-\mathrm{COOH}$ ) in aged binder [9].

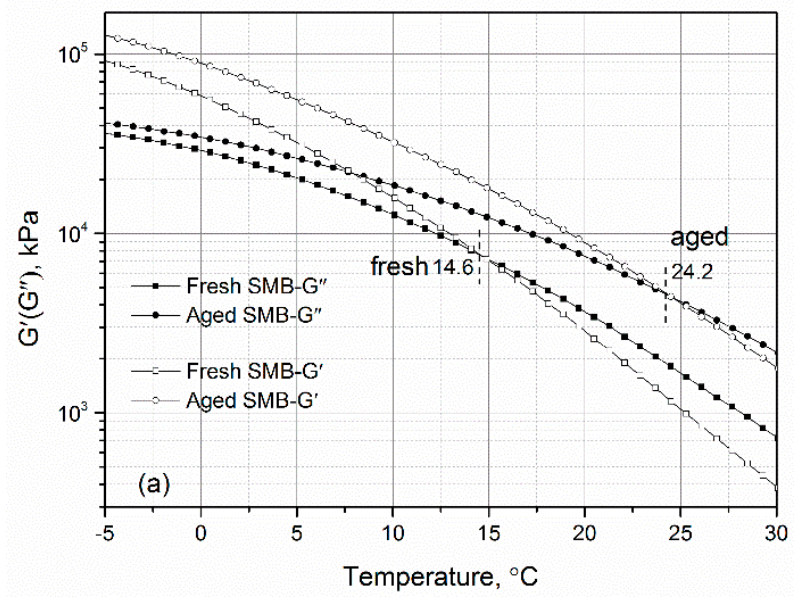

(a)

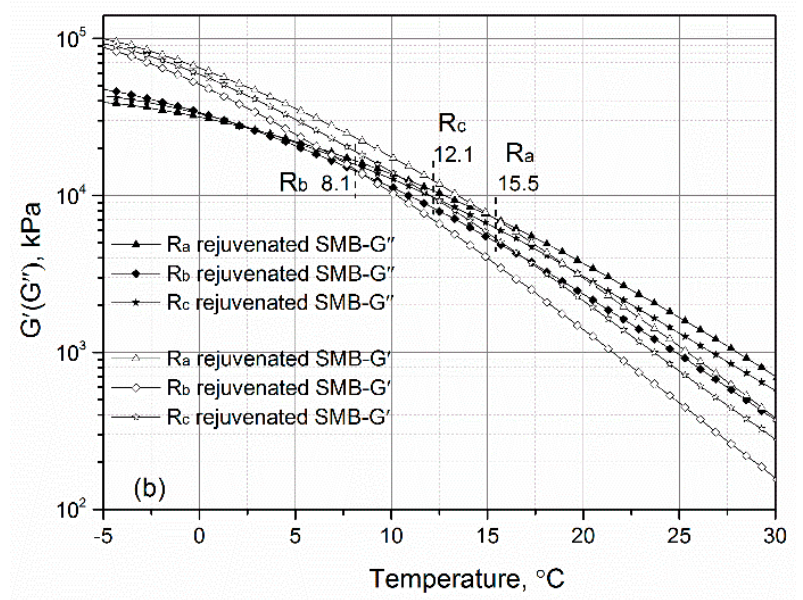

(b)

Figure 5. Viscous-elastic characteristics of (a) fresh and aged SMB and (b) rejuvenated SMB.

\subsection{Effect of Rejuvenating Systems on the Physical Properties of Aged SMB}

The loss tangent $(\tan \delta)$ is a vital indicator used to depict the damping loss of materials. Figure 6 displays its tendency and changing law for various bitumen specimens containing fresh, aged, and rejuvenated types. Useful and interesting information obtained from the figure is that the loss tangent of fresh SMB decreased with aging, however, to a certain degree, the loss tangent of aged SMB increased with rejuvenation. In other words, with the hardening of fresh SMB during the aging period, the damping loss was be reduced on the basis of elastic energy storage, and when the aged SMBs were rejuvenated with $R_{a}, R_{b}$, and $R_{c}$, the damping loss was recover to a higher level. These results indicate that the vibration consumption of aged SMB containing rejuvenating systems may give them potential for use in reducing tire-ground noise. Differences in the damping loss of rejuvenated SMB incorporating $R_{b}$ and $R_{c}$ can mainly be attributed to the fact that the chemical reactions between isocyanate and aged SMB cause the partial hardening of the mixes, leading to a decrement of the viscous loss. 


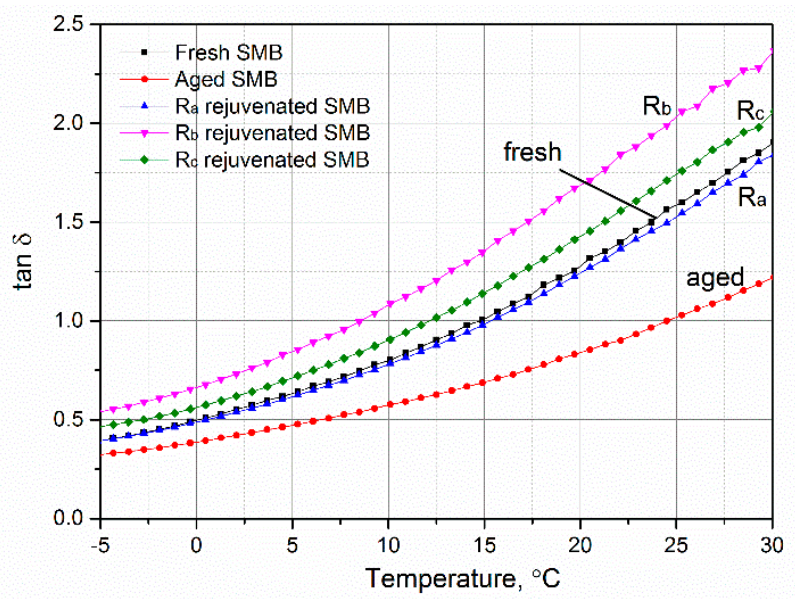

Figure 6. Effect of rejuvenating systems on the loss tangent of aged SMB.

\subsection{Effect of Rejuvenating Systems on the Complex Modulus and Phase Angle of Aged SMB}

The complex modulus and phase angle of aged SMB with rejuvenating systems are displayed in Figure 7 . In the temperature region between -5 and $30^{\circ} \mathrm{C}$, the complex modulus and phase angle of fresh $\mathrm{SMB}$ respectively increased and decreased after aging. With rejuvenation, the complex modulus recovered to that of the original or lower level of fresh $\mathrm{SMB}$, while the phase angle increased to near to or greater than the level of the fresh SMB. Compared with $R_{c}, R_{b}$ had a more obvious role in promoting the temperature sensitivity of aged SMB. All of the results demonstrate that the rejuvenating systems, particularly $R_{b}$, can activate the transfer of the hard components to the soft components in aged SMB, allowing superior rheological characteristics to be obtained.

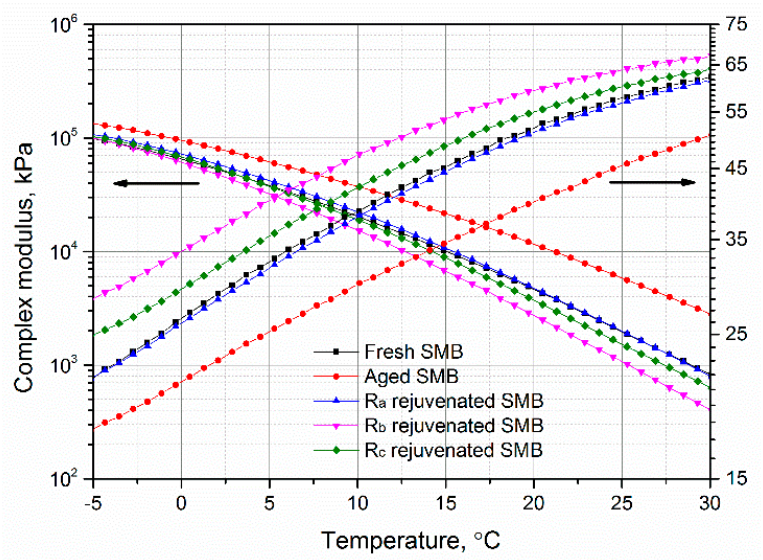

Figure 7. Effect of rejuvenating systems on the complex modulus and phase angle of aged SMB.

\subsection{Effect of Rejuvenating Systems on Rutting Factor of Aged SMB}

Figure 8 shows the rutting factors of aged SMB incorporating $R_{a}, R_{b}$, and $R_{c}$ with increasing temperature. The temperature points inserted in this figure refer to the requirements of the SHRP specification. It can be seen that the rutting factor of fresh SMB visibly increased after aging, while the rutting factor reduced with rejuvenation, among which rejuvenated SMB containing $R_{b}$ exhibited the greatest decrease. The results obtained indicate that the rejuvenation systems, especially $R_{b}$, had significant effects in decreasing the high-temperature characteristics of aged SMB. The findings show that depending upon the low-viscosity epoxy components in $R_{b}$, it can easily permeate into the aged binder and disperse the agglomerated substances formed by aging. Additionally, from the inserted figure, it can be seen that the rutting factor of rejuvenated SMB containing $R_{c}$ was somewhat higher in comparison with that containing $R_{b}$, demonstrating that the chemical reaction between $R_{c}$ and aged 
SMB can cause an increase in the rutting factor, and thus improve the high-temperature deformation resistance of rejuvenated binder.

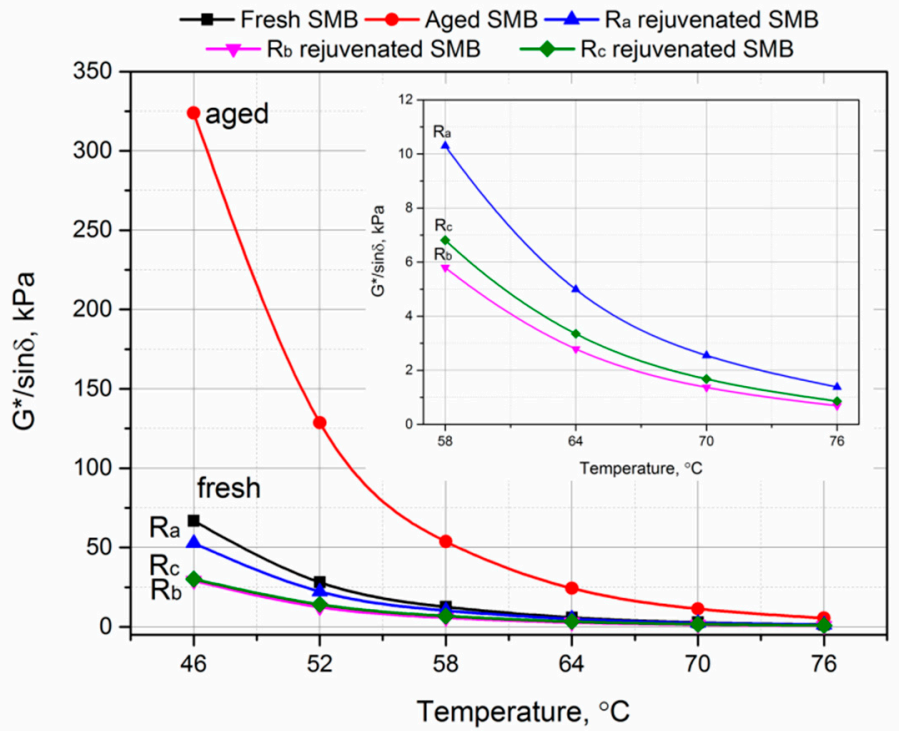

Figure 8. Rutting factor $\left(\mathrm{G}^{*} / \sin \delta\right)$ of fresh, aged, and rejuvenated SMB versus temperature.

\subsection{Effect of Rejuvenation System on the Phase Angle of Second-Aged SMB}

Due to better rejuvenation of aged SMB with $R_{c}$ according to the discussions above, the research on the rheological properties of second-rejuvenated SMB is continued in this section. Figure 9 shows the effect of $R_{c}$ on the phase angle of second-aged SMB. By comparing the phase angle trends of second-aged and rejuvenated SMB, it can be clearly obtained that the obvious differences of the phase angle were observed before approximately $50{ }^{\circ} \mathrm{C}$ (namely, the consistently higher phase angle of second-rejuvenated $\mathrm{SMB}$ ), while the value of second-rejuvenated SMB was more similar to the fresh one. The results indicate that the flow behaviors of second-aged SMB can be restored by this kind of rejuvenation system. Regarding the first-rejuvenated SMB containing $\mathrm{R}_{\mathrm{c}}$, four phase angle-temperature points $\left(-5,5,25\right.$, and $\left.60{ }^{\circ} \mathrm{C}\right)$ were selected to comparatively analyze the rejuvenation ability of $\mathrm{R}_{\mathrm{c}}$. At these four positions, the second-rejuvenated SMB consistently exhibited a lower rheological characteristic when compared with the first-rejuvenated one, which indicates that the rejuvenation ability of $R_{c}$ was weakened for second-aged SMB. To summarize, this type of rejuvenation system is still effective and useful to recover the rheological properties, and manifests better rejuvenation ability for second-aged SMB.

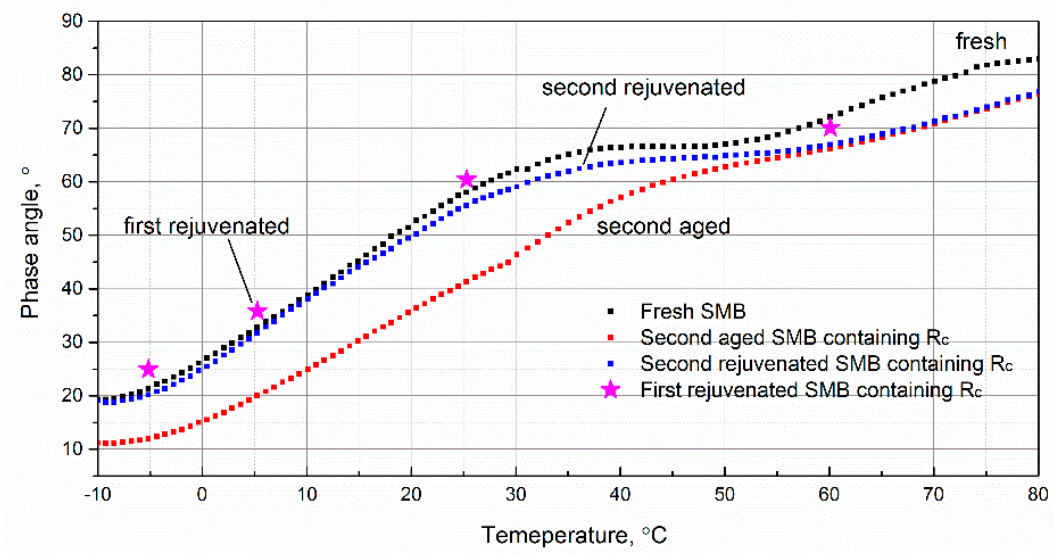

Figure 9. Effect of rejuvenating system on the phase angle of second-aged SMB. 


\subsection{Effect of Rejuvenation System on the Damping Loss of Second-Aged SMB}

The two temperatures of $5{ }^{\circ} \mathrm{C}$ and $60^{\circ} \mathrm{C}$ were selected as references to investigate the low- and high-temperature viscous damping loss of first- and second-rejuvenated SMB containing $\mathrm{R}_{\mathrm{c}}$, the data of which are presented in Table 3. As can be seen, regardless of whether the temperature was at 5 or $60^{\circ} \mathrm{C}$, the values of second-rejuvenated SMB were relatively lower when compared with the first-rejuvenated one. The results indicate that the viscous damping loss and deformation degree of second-rejuvenated SMB cannot recover to those of the first rejuvenation, but that second-rejuvenated SMB can also show relatively good rheological properties. The explanation for this is that the re-aging and re-rejuvenation bring about the agglomeration of higher-weight components and reaction-consolidation substances formed in the asphalt binder, and thus affect the consumption of vibration energy through the viscous loss of second-rejuvenated SMB.

Table 3. Loss tangent of first- and second-rejuvenated SMB containing $10 \% \mathrm{FCC} / 3 \% \mathrm{AGE} / 1 \% \mathrm{MDI}\left(\mathrm{R}_{\mathrm{c}}\right)$ at $5{ }^{\circ} \mathrm{C}$ and $60^{\circ} \mathrm{C}$.

\begin{tabular}{ccccc}
\hline Samples & \multicolumn{2}{c}{$\delta,^{\circ}$} & \multicolumn{2}{c}{ Tan $\delta$} \\
\hline & $5{ }^{\circ} \mathrm{C}$ & $60{ }^{\circ} \mathrm{C}$ & $5{ }^{\circ} \mathrm{C}$ & $60{ }^{\circ} \mathrm{C}$ \\
First-rejuvenated SMB containing $\mathrm{R}_{\mathrm{c}}$ & 35.8 & 70.1 & 0.72 & 2.76 \\
Second-rejuvenated SMB containing $\mathrm{R}_{\mathrm{c}}$ & 31.8 & 66.9 & 0.62 & 2.34 \\
\hline
\end{tabular}

\section{Conclusions}

This research aimed to achieve the high-quality performance recovery of aged SMB using rejuvenating systems consisting of FCC slurry, AGE, MDI, and other additives. The physical and rheological properties of rejuvenated SMB were systematically investigated and evaluated. Some worthy and interesting results are summarized below:

1. Both $R_{b}$ and $R_{c}$ rejuvenation systems of had significant advantages in contributing to improving the physical properties, including the ductility, penetration, and viscosity of aged SMB, while slightly reducing the softening point. Meanwhile, these kinds of rejuvenating systems were proved to still be applicable in the re-rejuvenation of re-aged binder.

2. The results of viscous-elastic temperatures indicate that oxidative aging promotes the hardening caused from the agglomeration of binder molecules for fresh SMB, which leads to a sharp increase of the viscous-elastic temperature. However, with the rejuvenating systems, particularly $R_{b}$, the viscous-elastic temperature of rejuvenated SMB could be somewhat reduced to improve the low-temperature crack resistance.

3. The obtained results on rutting factors indicate that the rejuvenating systems, especially $R_{b}$ and $\mathrm{R}_{\mathrm{c}}$, are harmful to the high-temperature deformation resistance of rejuvenated SMB, but their performance level can still be close to that of fresh SMB with changing temperature.

4. The results of damping loss demonstrated that vibration consumption for noise was improved for aged $\mathrm{SMB}$ with incorporated $\mathrm{R}_{\mathrm{b}}$ and $\mathrm{R}_{\mathrm{c}}$ in the form of viscous loss, and furthermore, the effects for re-aged SMB using the same rejuvenating systems were weakened but still effective.

5. We recommend the use of rejuvenating systems containing epoxy-with or without isocyanate-for recycling aged SBS asphalt binder for application in the mid-temperature region. The disadvantage of rejuvenated binder lies in its poorer high-temperature workability. Despite that, more considerations regarding the performance restoration of degraded polymer in binder should be examined in future work.

Author Contributions: Z.L., X.X. and J.Y. conceived and designed the experiments; Z.L. and X.X. performed the experiments; Z.L., X.X., J.Y. and S.W. analyzed the data; J.Y. and S.W. contributed reagents/materials/analysis tools; Z.L. wrote this paper. 
Funding: This research was funded by the Fundamental Research Funds for the Central Universities (2016-YB-010).

Acknowledgments: This work is supported by the Fundamental Research Funds for the Central Universities (2016-YB-010). The authors gratefully acknowledge the financial support. Thanks are also honestly due to my supervisor's responsibility for the experienced test and paper writing. We are very grateful for the help from our research project groups.

Conflicts of Interest: The authors declare no conflict of interest.

\section{References}

1. Zhao, X.Y.; Wang, S.F.; Wang, Q.; Yao, H.R. Rheological and structural evolution of SBS modified asphalts under natural weathering. Fuel 2016, 184, 242-247. [CrossRef]

2. Durrieu, F.; Farcas, F.; Mouillet, V. The influence of UV aging of a styrene/butadiene/styrene modified bitumen: Comparison between laboratory and on site aging. Fuel 2007, 86, 1446-1451. [CrossRef]

3. Cong, P.; Luo, W.; Xu, P.; Zhao, H. Investigation on recycling of SBS modified asphalt binders containing fresh asphalt and rejuvenating agents. Constr. Build. Mater. 2015, 91, 225-231. [CrossRef]

4. Xu, X.; Yu, J.Y.; Wang, R.Y.; Hu, J.X.; Xue, L.H. Investigation of road performances of reaction-rejuvenated SBS modified bitumen mixture. Constr. Build. Mater. 2018, 183, 523-533. [CrossRef]

5. Xiao, F.P.; Putman, B.; Amirkhanian, S. Rheological characteristics investigation of high percentage RAP binders with WMA technology at various aging states. Constr. Build. Mater. 2015, 98, 315-324. [CrossRef]

6. Yan, C.Q.; Xiao, F.P.; Huang, W.; Quan, L. Critical matters in using Attenuated Total Reflectance Fourier Transform Infrared to characterize the polymer degradation in Styrene-Butadiene-Styrene-modified asphalt binders. Polym. Test. 2018, 70, 289-296. [CrossRef]

7. Xu, S.; Yu, J.Y.; Hu, C.B.; Qin, D.F.; Xue, L.H. Laboratory evaluation of rejuvenation effect of reactive rejuvenator on aged SBS modified bitumen. Mater. Struct. 2017, 50, 233. [CrossRef]

8. Nian, T.F.; Li, P.; Wei, X.Y.; Wang, P.H.; Li, H.S.; Guo, R. The effect of freeze-thaw cycles on durability properties of SBS-modified bitumen. Constr. Build. Mater. 2018, 187, 77-88. [CrossRef]

9. Xu, X.; Yu, J.Y.; Xue, L.H.; He, B.Y.; Du, W.; Zhang, H.; Li, Y. Effect of reactive rejuvenating system on physical properties and rheological characteristics of aged SBS modified bitumen. Constr. Build. Mater. 2018, 176, 35-42. [CrossRef]

10. Poulikakos, L.D.; Santos, S.; Bueno, M.; Kuentzel, S.; Hugener, M.; Partl, M.N. Influence of short and long term aging on chemical, microstructural and macro-mechanical properties of recycled asphalt mixtures. Constr. Build. Mater. 2014, 51, 414-423. [CrossRef]

11. Xu, X.; Yu, J.Y.; Zhang, C.L.; Cao, Z.L.; Gu, Y.; Xue, L.H. Effect of reactive rejuvenators on structure and properties of UV-aged SBS modified bitumen. Constr. Build. Mater. 2017, 155, 780-788. [CrossRef]

12. Singh, S.K.; Kumar, Y.; Ravindranath, S.S. Thermal degradation of SBS in bitumen during storage: Influence of temperature, SBS concentration, polymer type and base bitumen. Polym. Degrad. Stabil. 2018, 147, 64-75. [CrossRef]

13. Wang, T.; Xiao, F.P.; Amirkhanian, S.; Huang, W.D.; Zheng, M.L. A review on low temperature performances of rubberized asphalt materials. Constr. Build. Mater. 2017, 145, 483-505. [CrossRef]

14. Hao, J.T.; Cao, P.Y.; Liu, Z.H.; Wang, Z.X.; Xia, S.F. Developing of a SBS polymer modified bitumen to avoid low temperature cracks in the asphalt facing of a reservoir in a harsh climate region. Constr. Build. Mater. 2017, 150, 105-113. [CrossRef]

15. RRasool, T.; Yao, H.R.; Hassan, A.; Wang, S.F.; Zhang, H.Y. In-field aging process of high content SBS modified asphalt in porous pavement. Polym. Degrad. Stabil. 2018, 155, 220-229. [CrossRef]

16. Chen, M.Z.; Xiao, F.P.; Putman, B.; Leng, B.B.; Wu, S.P. High temperature properties of rejuvenating recovered binder with rejuvenator, waste cooking and cotton seed oils. Constr. Build. Mater. 2014, 59, 10-16. [CrossRef]

17. Zhu, H.; Xu, G.; Gong, M.; Yang, J. Recycling long-term-aged asphalts using bio-binder/plasticizer-based rejuvenator. Constr. Build. Mater. 2017, 147, 117-129. [CrossRef]

18. Qiu, Y.J.; Ding, H.B.; Rahman, A.; Wang, W.Q. Damage characteristics of waste engine oil bottom rejuvenated asphalt binder in the non-linear range and its microstructure. Constr. Build. Mater. 2018, 174, 202-209. [CrossRef] 
19. Asli, H.; Ahmadinia, E.; Zargar, M.; Mohamed, R.K. Investigation on physical properties of waste cooking oil-rejuvenated bitumen binder. Constr. Build. Mater. 2012, 37, 398-405. [CrossRef]

20. Zargar, M.; Ahmadinia, E.; Asli, H.; Karim, M.R. Investigation of the possibility of using waste cooking oil as a rejuvenating agent for aged bitumen. J. Hazard. Mater. 2012, 233, 254-258. [CrossRef]

21. Gong, M.H.; Yang, J.; Zhang, J.Y.; Zhu, H.R.; Tong, T.Z. Physical-chemical properties of aged asphalt rejuvenated by bio-oil derived from biodiesel residue. Constr. Build. Mater. 2016, 105, 35-45. [CrossRef]

22. Chen, M.Z.; Leng, B.B.; Wu, S.P.; Sang, Y. Physical, chemical and rheological properties of waste edible vegetable oil rejuvenated asphalt binders. Constr. Build. Mater. 2014, 66, 286-298. [CrossRef]

23. Xu, X.; Yu, J.Y.; Xue, L.H.; Zhang, C.L.; Zha, Y.G.; Gu, Y. Investigation of Molecular Structure and Thermal Properties of Thermo-Oxidative Aged SBS in Blends and Their Relations. Materials 2017, 10, 768. [CrossRef] [PubMed]

24. Xu, X.; Yu, J.Y.; Zhang, C.L.; Xu, S.; Xue, L.H.; Xie, D. Investigation of aging behavior and thermal stability of styrene-butadiene-styrene tri-block copolymer in blends. Polymer (Korea) 2016, 40, 947-953. [CrossRef]

25. Wu, S.P.; Pang, L.; Mo, L.T.; Chen, Y.C.; Zhu, G.J. Influence of aging on the evolution of structure, morphology and rheology of base and SBS modified bitumen. Constr. Build. Mater. 2009, 23, 1005-1010. [CrossRef]

26. Singh, R.P.; Desai, S.M.; Solanky, S.S.; Thanki, P.N. Photodegradation and stabilization of styrene-butadiene-styrene rubber. J. Appl. Polym. Sci. 2000, 75, 1103-1114. [CrossRef]

27. Standard Practice for Accelerated Aging of Asphalt Binder Using a Pressurized Aging Vessel (PAV); ASTM D6521; ASTM International: West Conshohocken, PA, USA, 2018.

28. Standard Test Method for Viscosity Determination of Asphalt at Elevated Temperatures Using a Rotational Viscometer; ASTM D4402; ASTM International: West Conshohocken, PA, USA, 2015.

29. Standard Test Method for Softening Point of Bitumen (Ring-and-Ball Apparatus); ASTM D36; ASTM International: West Conshohocken, PA, USA, 2014.

30. Standard Test Method for Penetration of Bituminous Materials; ASTM D5; ASTM International: West Conshohocken, PA, USA, 2013.

31. Standard Test Method for Ductility of Asphalt Materials; ASTM D113; ASTM International: West Conshohocken, PA, USA, 2017.

(C) 2019 by the authors. Licensee MDPI, Basel, Switzerland. This article is an open access article distributed under the terms and conditions of the Creative Commons Attribution (CC BY) license (http://creativecommons.org/licenses/by/4.0/). 